\title{
Better or Worse? Despite Progress, Many Africans Still Finds It Difficult in Accessing Health Care: A Comparative Analysis of Eight African Countries
} Isaac Adisah-Atta ${ }^{1^{*}}$ and Henry Ofori Duah ${ }^{2}$

${ }^{1}$ Department of Political Studies, University of Saskatchewan, Canada

${ }^{2}$ Clinical Research Coordinator, Foundation of Orthopaedic and Complex Spine (FOCOS) Hospital, Ghana

\begin{abstract}
Citizens' perceptions in this analysis suggest a number of barriers to health-care access and utilization across the eight African countries studied. On average, across the 8 countries, Afrobarometer fieldworkers did not find health facilities in about $40 \%$ of all the enumeration areas (EA) included in the survey. Generally, across the 8 countries, about $34 \%$ of the respondents reported that they "could not have contact" for health care when there needed it. Among those who accessed health care during the previous year, a cumulative $31 \%$ found it "difficult" or "very difficult" to get the care they needed. Averagely, only $14 \%$ of all the respondents surveyed indicated that they obtained their needed medical care " right way" implying that a significant proportion of people wasted "longer time" prior to receiving their health care needs. Close to half $(46 \%)$ of citizens in the eight countries noted that their governments were performing "fairly badly" or "very badly" as far as improving basic health services were concerned with only $10 \%$ of the citizens said their government were performing very well. In all the 8 countries tracked since 2005, negative evaluations of their governments have increased by about 13 percentage points over the past decade. Therefore, governments in the African sub-region need to enhance their efforts to promote accessibility to basic health care services which is a fundamental human right enshrined in the Alma-Ata Declaration.
\end{abstract}

Keywords: Healthcare; Health services; Human resources

\section{Summary}

Many sub-Saharan African countries are experiencing appreciable improvement in their respective economies after many years of economic stagnation. Within the past two decades, many African states are recording encouraging growth rates in Gross Domestic Product (GDP) and positive policy improvements [1]. For example, according to the OECD and African Economic Outlook (AEU) report in 2006 and 2017 respectively, GDP growth rates hover around 5 to 6 percent per annum-with global comparison, and this has brought greater economic stability in many African countries [2,3]. These positive trends in economic growth and stability are good news for efforts to reduce poverty and improve health outcomes in Africa. Despite these encouraging improvements, Africa tops the list as the region with perhaps greater health inefficiencies [4]. This poor population health status is mirrored by crises in health financing and human resources for health. With only 2 percent of the global health workforce and only 1 percent of the world's health expenditures [5], health systems in sub-Saharan African countries are ill-equipped to adequately address their health problems. Low per capita income and limited capacity for domestic revenue mobilization have complicated many governments' ability to respond effectively to the health challenges in in many SubSaharan African Countries [6].

In Afrobarometer surveys across 36 African countries in 2014/2015, citizens ranked health care as the second-most-important problem (after unemployment) that their governments needed to address, as well as the number 2 priorities (after education) that required additional government investment [7]. While the proportion of Africans going without needed health care has decreased over the past decade, citizens' perceptions highlight some of the challenges that still stand between current reality and the slogan of "health for all," including: In many areas, a continued absence of basic health-care facilities, shortages of needed medical care experienced by almost half of all Africans, widespread difficulties encountered in obtaining care, and this sometimes compel patients to pay bribes, poor government performance, according to citizen ratings, in improving basic health services [7]. Though previous Afrobarometer surveys (2005-2015) have reported inefficiencies in healthcare provision in Africa as well as difficulties in accessing healthcare by citizens in Africa, this current communication paper uses the current round 7 (2016/2018) survey data to ascertain whether accessing health care in Africa is getting better or worse. Specifically, using eight African countries, this paper seeks to address the question of whether or not many Africans still finds it difficult in accessing health care.

\section{About Afrobarometer Survey}

Afrobarometer is a pan-African, non-partisan research network that conducts public attitude surveys on democracy, governance, economic conditions, and related issues across more than 30 countries in Africa. Five rounds of surveys were conducted between 1999 and 2014 and results from Round 7 surveys (2016/2018) are currently being released. Afrobarometer conducts face-to-face interviews in the language of the respondent's choice with nationally representative samples, which yield country-level results with a margin of sampling error of $+/-2 \%$ (for a sample of 2,400 ) or $+/-3 \%$ (for a sample of 1,200 ) at a $95 \%$ confidence level. Round 7 interviews with almost 54,000 citizens represent the views of more than three-fourths of the continent's population. This analysis draws mainly on Round 7 (2016/2018) data from 8 countries, with overtime comparisons on some variables. Interested readers should visit http://globalreleases. afrobarometer.org/ for previous rounds.

*Corresponding author: Isaac Adisah-Atta, Department of Political Studies, University of Saskatchewan, 283C Arts Building, Saskatoon, SK S7N 5A5, Canada, Tel: +1-306-514-1078; E-mail: iaa408@mail.usask.ca

Received January 15, 2018; Accepted January 20, 2018; Published January 22, 2018

Citation: Adisah-Atta I, Duah HO (2018) Better or Worse? Despite Progress, Many Africans Still Finds It Difficult in Accessing Health Care: A Comparative Analysis of Eight African Countries. J Health Med Informat 9: 299. doi: 10.4172/21577420.1000299

Copyright: $\odot 2018$ Adisah-Atta I, et al. This is an open-access article distributed under the terms of the Creative Commons Attribution License, which permits unrestricted use, distribution, and reproduction in any medium, provided the original author and source are credited. 
Citation: Adisah-Atta I, Duah HO (2018) Better or Worse? Despite Progress, Many Africans Still Finds It Difficult in Accessing Health Care: A Comparative Analysis of Eight African Countries. J Health Med Informat 9: 299. doi: 10.4172/2157-7420.1000299

Page 2 of 4

\section{Presence of Health Clinics in Enumeration Areas}

As part of the assessment, Afrobarometer asked respondents whether health services were present in their primary sampling unit/enumeration area or in easy walking distance. Averagely, about $39.4 \%$ of respondents interviewed in all the eight African countries indicated that health services were not present in their enumeration areas (Figure 1).

Respondents were asked: Are the following services present in the primary sampling unit/enumeration area or in easy walking distance?

The highest in this regard were observed in Zambia and Côte d'Ivoire where slightly over $50 \%$ of respondents noted that health services were not present in their enumeration areas. However, only $28 \%$ and $29 \%$ of respondents in Uganda and Mali, respectively, indicated that health services were not present in their enumeration areas.

\section{Difficulty to obtain medical treatment}

As part of the assessment, Afrobarometer asked respondents how easy or difficult it was it to obtain the medical care when they needed it.

Generally, about $34 \%$ of respondents interviewed in all the eight African countries could not have contact for health care when there needed it. Moreover, $19.3 \%$ said it was difficult accessing health care when they needed it, $11.7 \%$ noted that it was very difficult in accessing medical care. Moreover, $24.7 \%$ noted it was easy whiles $10.3 \%$ to obtain the medical care they needed. The highest proportion of people who had no contact when they sought to obtain needed medical care was observed in Côte d'Ivoire (56.2\%), followed by Zimbabwe (40.5\%) whiles the lowest proportion was seen in Malawi (19.3\%) (Table 1).

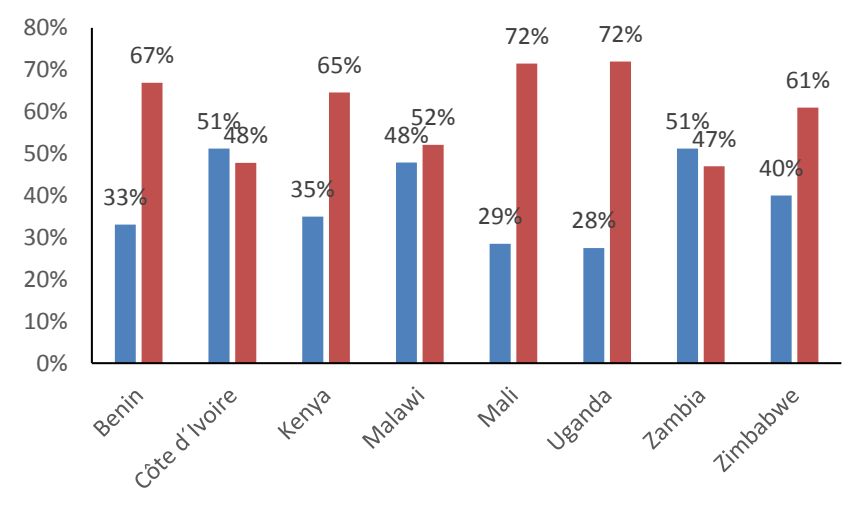

$\square$ No $\square$ Yes

Figure 1: Presence of Health clinics in enumeration areas: 8 Countries: 2016/2018.
Moreover, after stratification by place of residence, it was observed that urban residents are more likely than rural dwellers, on average, to say they had no contact when they needed health-care services $(38.84 \%$ vs. 32. 45\%). This pattern was seen in a majority of countries, led by Malawi (a 14.4 percentage-point gap), Zambia (11 points), Mali (5.9 points). However, in Côte d'Ivoire, more rural than urban dwellers had no contact when they sought to obtain their medical needs (a 4.0 percentage-point gap).

Moreover, across the 8 countries, men were more likely than women to report having no contact when they needed medical care $(37.5 \%$ vs. $31.06 \%)$. But the disparity is considerably larger in some countries: Zambian men were 10.8 percentage points more likely than their female counterparts to say they had no contact when the sought to obtain needed medical, Ugandan men (9.1 points), Kenyan men (7.5 points). However, in Mali women were 2.3 percentage points more likely than their male counterparts to say they had no contact when the sought to obtain needed medical (Figure 2 and Table 2).

Respondents were asked: How long did it take you to receive the medical care that you needed? Was it right away, after a short time, after a long time, or never had contact?

From the graph below, it can be seen across all the 8 countries that the proportion of people who had no contact when they sought health care was higher in 2014/2015 and 2016/2018 compared to 2005/2006

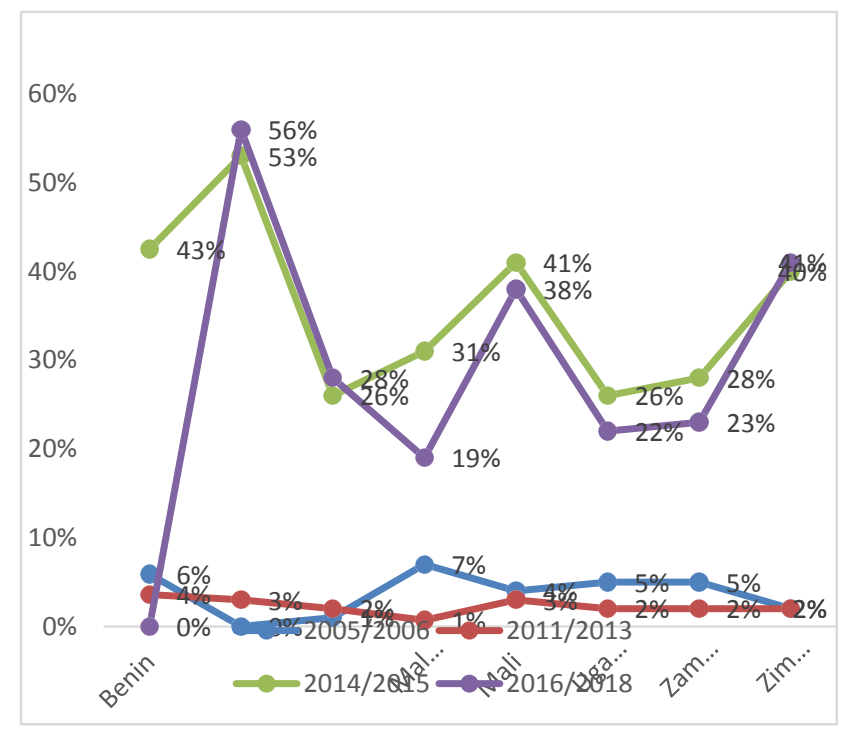

Figure 2: Trends of "No Contact" when people needed medical care: 8 Countries: 2005-2018.

\begin{tabular}{|c|c|c|c|c|c|c|c|c|c|}
\hline & & Country & & & & & & & \\
\hline Category & Total & Benin & $\begin{array}{c}\text { Côte } \\
\text { d'Ivoire }\end{array}$ & Kenya & Malawi & Mali & Uganda & Zambia & Zimbabwe \\
\hline Very easy & $10.3 \%$ & $11.1 \%$ & $4.5 \%$ & $8.7 \%$ & $9.5 \%$ & $18.1 \%$ & $7.8 \%$ & $14.3 \%$ & $8.8 \%$ \\
\hline Easy & $24.7 \%$ & $23.0 \%$ & $22.0 \%$ & $29.7 \%$ & $22.7 \%$ & $27.1 \%$ & $21.7 \%$ & $26.5 \%$ & $23.1 \%$ \\
\hline Difficult & $19.3 \%$ & $12.9 \%$ & $13.7 \%$ & $24.1 \%$ & $23.7 \%$ & $10.6 \%$ & $28.0 \%$ & $22.2 \%$ & $17.4 \%$ \\
\hline Very Difficult & $11.7 \%$ & $6.0 \%$ & $3.6 \%$ & $9.1 \%$ & $24.6 \%$ & $6.5 \%$ & $20.5 \%$ & $13.7 \%$ & $10.2 \%$ \\
\hline No contact & $34.0 \%$ & $47.0 \%$ & $56.2 \%$ & $28.3 \%$ & $19.3 \%$ & $37.6 \%$ & $22.0 \%$ & $23.2 \%$ & $40.5 \%$ \\
\hline Don't know & $0.1 \%$ & - & $0.1 \%$ & $0.1 \%$ & $0.2 \%$ & - & - & $0.1 \%$ & $0.1 \%$ \\
\hline
\end{tabular}

(N) 9,992 (100\%) 1,200 (100\%) 1,200 (100\%) 1,599 (100\%) 1,200 (100\%) 1,200 (100\%) 1,200 (100\%) 1,193 (100\%) 1,200 (100\%) Data source: Afrobarometer survey, 2016/2018

Table 1: How easy or difficult was it to obtain the medical care you needed? 
Citation: Adisah-Atta I, Duah HO (2018) Better or Worse? Despite Progress, Many Africans Still Finds It Difficult in Accessing Health Care: A Comparative Analysis of Eight African Countries. J Health Med Informat 9: 299. doi: 10.4172/2157-7420.1000299

Page 3 of 4

\begin{tabular}{|c|c|c|c|c|c|c|}
\hline & \multicolumn{6}{|c|}{ No contact when they sought to obtain medical care } \\
\hline & Urban & Rural & $\begin{array}{c}\text { Urban-Rural Gap } \\
\text { (percentage points) }\end{array}$ & Male & Female & $\begin{array}{c}\text { Male -Female Gap } \\
\text { (percentage points) }\end{array}$ \\
\hline Benin & $48.5 \%$ & $45.6 \%$ & +2.9 & $49.6 \%$ & $44.3 \%$ & +5.3 \\
\hline Côte d'Ivoire & $54.2 \%$ & $58.2 \%$ & -4.0 & $59.4 \%$ & $53.1 \%$ & +6.3 \\
\hline Kenya & $34.7 \%$ & $24.7 \%$ & +10 & $32.1 \%$ & $24.6 \%$ & +7.5 \\
\hline Malawi & $31.7 \%$ & $17.3 \%$ & +14.4 & $23.8 \%$ & $14.9 \%$ & +8.9 \\
\hline Mali & $42.2 \%$ & $36.3 \%$ & +5.9 & $36.5 \%$ & $38.8 \%$ & -2.3 \\
\hline Uganda & $26.3 \%$ & $20.6 \%$ & +5.7 & $26.6 \%$ & $17.5 \%$ & +9.1 \\
\hline Zambia & $29.3 \%$ & $18.3 \%$ & +11 & $28.5 \%$ & $17.7 \%$ & +10.8 \\
\hline Zimbabwe & $43.8 \%$ & $38.6 \%$ & +5.2 & $43.5 \%$ & $37.6 \%$ & +5.9 \\
\hline
\end{tabular}

Data source: Afrobarometer survey, 2016/2018

Table 2: Proportion who had no contact when they sought to obtain medical care: by place of residence and Gender.

and 2011/2013 rounds of the Afrobarometer survey. The proportion of "no contacts" for Côte d'Ivoire and Benin were consistently over $40 \%$ in both 2014/2015 and 2016/2018 rounds. The was very small difference in the proportion of "no contacts" across the countries except for Malawi which witnessed about $11 \%$ increase in the percentage on "no contacts" from 2005/2006 to 2011/2013 Afrobarometer survey rounds.

\section{Better or worse: Access to medical care}

As part of the assessment, Afrobarometer asked respondents to tell if their ability to get medical care when they needed it are worse or better now than they were a few years ago, or whether they were about the same. Averagely, across the eight countries, $34 \%$ noted that their ability to get medical care is better compared to few years ago. The highest in this regard was seen in Kenya (51\%) and Mali (42\%) whiles only $26 \%$ in Malawi said that their ability to get medical care is better compared to few years ago (Figure 3 ).

Respondents were asked: Please tell me if the following things are worse or better now than they were a few years ago, or are they about the same? Your ability to get medical care when you need it

It is again worth noting that averagely across the 8 countries, $21 \%$ noted that their ability to get medical care is worse compared to few years ago. Similarly, disparities were observed in this regard. The highest was seen in Malawi and Uganda where 27\% their population noted that their ability to get medical care is worse compared to few years ago. Only $13 \%$ of Kenyans said that their ability to get medical care is worse compared to few years ago.

\section{Time taken to receive medical care}

As part of the assessment, Afrobarometer asked respondents about experiences that they had in accessing certain essential government services. Especially, regarding how long it took them to receive the medical care that they needed. Whether they had it right away, after a short time, after a long time, or never (Figure 4).

Respondents were asked: How long did it take you to receive the medical care that you needed? Was it right away, after a short time, after a long time, or never?

Averagely, across the eight countries, $26 \%$ indicated that it took a long time for them to obtain medical care when they needed it. The highest in this regard was observed in Malawi and Uganda where $45 \%$ and $42 \%$ respectively noted that it took a long time to obtain medical care when they needed it. In Mali only $12 \%$ indicated that it took a long time to obtain medical care when they needed it. However, averagely

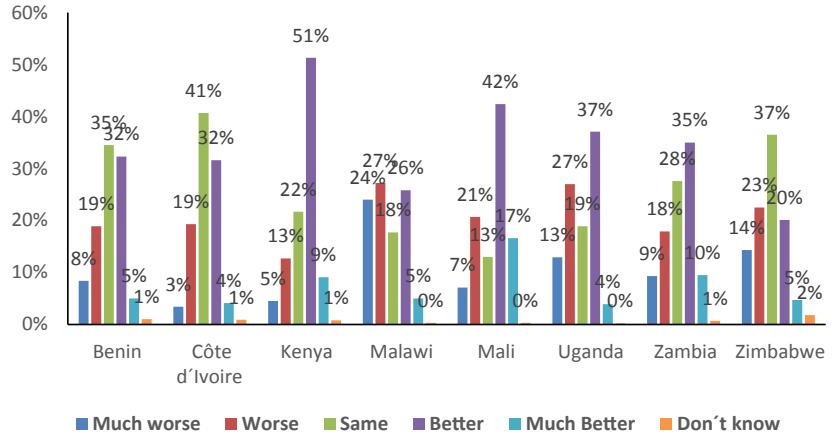

Figure 3: Better or worse: access to medical care: 8 Countries: 2016/2018.

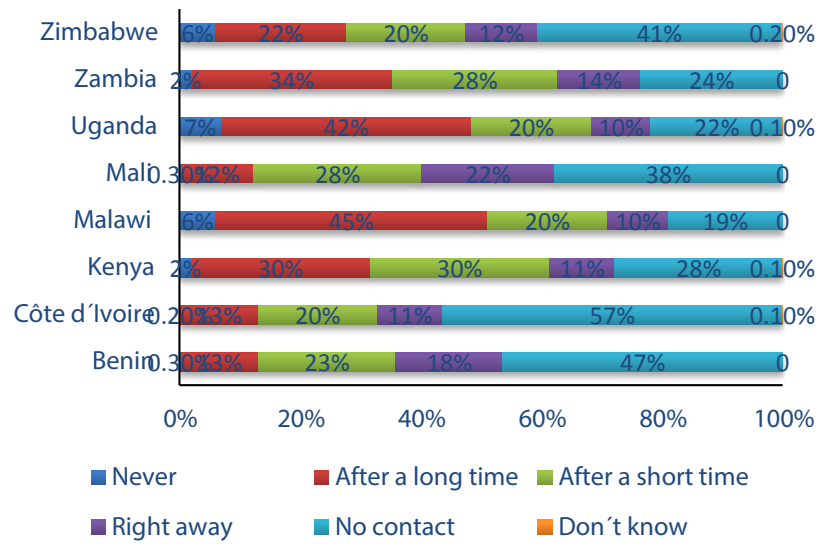

Figure 4: Time taken to receive medical care: 8 Countries: 2016/2018.

$24 \%$ of people in all the 8 countries indicated that they obtained their needed medical care after a short time. The highest in this regard was seen in Kenya and Zambia where $30 \%$ and $28 \%$, respectively said that they obtained their needed medical care after a short time. However, $20 \%$ of people in Zimbabwe, Côte d'Ivoire, Uganda and Malawi said they obtained their needed medical care after a short time. Averagely, only $14 \%$ of people in all the 8 countries indicated that they obtain the needed medical care right way.

\section{Handling improving basic health services by their respective governments}

Afrobarometer also sought the views of people in the 8 countries as to how well or badly they would you say their current governments are 


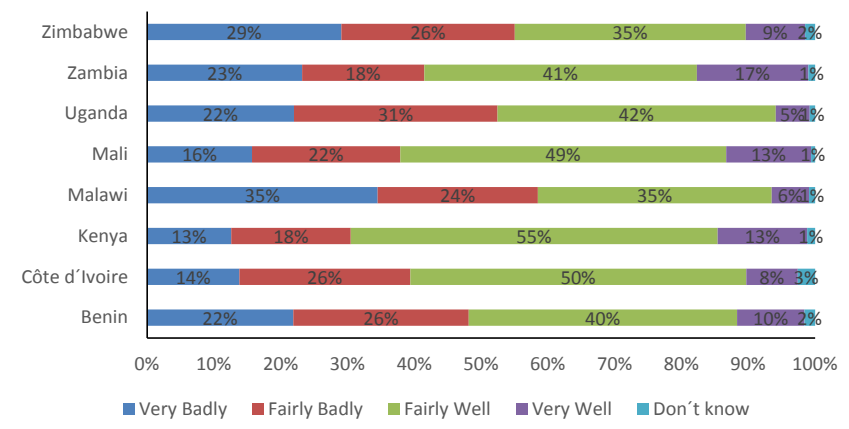

Figure 5: Handling and improving basic services by governments: 8 Countries: 2016/2018.

handling improvement in basic health services. Averagely, across the 8 countries, $43 \%$ of people indicated that their governments are doing fairly well to improve basic health services. The highest was seen in Kenya and Côte d'Ivoire where $55 \%$ and $50 \%$, respectively noted that their governments are doing fairly well to improve basic health services (Figure 5).

Respondents were asked: How well or badly would you say the current government is handling the following matters, or haven't you heard enough to say? Improving basic health services

Moreover, on average, $22 \%$ of the people across all the 8 countries indicated that their government have performed very badly in improving the basic health services. The highest in this regard was seen in Malawi and Zimbabwe where $35 \%$ and $29 \%$ respectively noted that their governments have performed very badly in improving the basic health services. Moreover, averagely across the 8 countries $24 \%$ said that their governments have performed fairly badly in improving the basic health services. This was led by Uganda where $31 \%$ indicated that their government has performed very badly in improving the basic health services. On average only $10 \%$ of people across the 8 countries noted that their governments have performed very well in improving the basic health services.

\section{Conclusion}

The indicators reported in this paper generally revealed disparities in the accessibility of health services across eight African countries. While this sample does to give a holistic image of health access in Africa, it reveals that government in the African region needs to enhance their efforts to promote accessibility to basic health care services which is a fundamental human right enshrined in the Alma-Ata Declaration. Overall, citizen ratings of government efforts in all the eight countries are fairly negative - significantly more negative than a decade ago. Experiences and perceptions of health care vary widely by country, and more specific data are needed to identify the most important kinds of difficulties that patients encounter as well as the factors that explain negative public perceptions of government performance. But citizens speak clearly in saying that health care is one of their top priorities for government action.

\section{References}

1. Adisah-Atta I (2017) Financing Health Care in Ghana: Are Ghanaians Willing to Pay Higher Taxes for Better Health Care? Findings from Afrobarometer. Social Sciences 6: 90.

2. World Bank (2017) African Development Indicators. Washington: World Bank Group.

3. OECD (Organisation for Economic Co-operation and Development) (2016) Development Centre and the African Development Bank. African Economic Outlook.

4. https://www.wilsoncenter.org/sites/default/files/Kaseje2.pdf

5. Gottret P, Schieber G (2006) Health Financing Revisited: A Practitioner's Guide. Washington: World Bank.

6. Bart C, Waelkens MP, Soors W, Devadasan N, Atim C (2008) Community health insurance in developing countries. Int Encyclo Pub Healt 1: 782-791.

7. Armah-Attoh D, Selormey E, Houessou R (2016) Despite gains, barriers keep health care high on Africa's priority list. Policy Paper 1: 31. 